\title{
Bioactivity of cement type bone substitutes
}

\author{
D. SIEK ${ }^{1}$, J. CZECHOWSKA ${ }^{1}$, W. MRÓZ2 ${ }^{2}$ A. ZIMA ${ }^{1}$, S. BURDYŃSKA ${ }^{2}$, \\ R. ZAŁĘCZNY ${ }^{2}$, and A. ŚLÓSARCZYK ${ }^{1 *}$ \\ ${ }^{1}$ Faculty of Materials Science and Ceramics, AGH University of Science and Technology, 30 Mickiewicza Ave, 30-059, Krakow, Poland \\ ${ }^{2}$ Institute of Optoelectronics, Military Academy of Technology, 2 Gen. Sylwestra Kaliskiego Ave, 00-908 Warsaw 2, Poland
}

\begin{abstract}
In vitro chemical stability and bioactivity of three different cement type bone substitutes were determined by incubating cement samples in the simulated body fluid (SBF) for 7 and 28 days. Morphology of sample surfaces has been studied using scanning electron microscopy (SEM) combined with an energy dispersive X-ray spectroscopy (EDS) and by atomic force microscopy (AFM). The diffuse reflectance Fourier-transform infrared spectroscopy (DRIFTS) was applied as a supplementary method. The development of bone-like apatite layers on the surface depended on their initial phase composition. Obtained cements showed good surgical handiness, high bioactive potential and were chemically stable. They seem to be promising materials for bone substitution.
\end{abstract}

Key words: bone implants, bioactivity, surface morphology.

\section{Introduction}

Biomaterials designed for filling bone defects should be biocompatible, bioresorbable and exhibit osteoconductive, osteogenic and osteoinductive properties. Bone substitutes should possess mechanical properties matching those of the tissue, be easy-to-handle and cost-effective [1-3]. Bioactivity of these materials is considered as an essential property required for successful in vivo implantation $[4,5]$. Bioactive materials are defined as materials which induce a specific biological response at the material/tissue interface [6]. Such materials bonds to living bone through an apatite layer which is formed on their surfaces after implantation [7, 8]. The layer consists of low-crystallinity calcium-deficient and carbonatecontaining hydroxyapatite.

Formation of a chemical bond between the bone apatite and the surface apatite on bioactive materials reduces the interfacial energy $[9,10]$. In vivo bioactivity of implant materials can be predicted by assessing the apatite formation on their surfaces during in vitro tests performed in the simulated body fluid (SBF) [4].

Calcium phosphates (CaPs), such as hydroxyapatite (HA) - $\mathrm{Ca}_{10}\left(\mathrm{PO}_{4}\right)_{6}(\mathrm{OH})_{2}$ and tricalcium phosphate (TCP) $\mathrm{Ca}_{3}\left(\mathrm{PO}_{4}\right)_{2}$, are widely used in the hard tissue replacement primarily because of their chemical composition and structural similarity to natural bone minerals and due to their excellent biocompatibility and bioactivity $[11,12]$. Tricalcium phosphate comes in two forms, i.e. alpha and beta TCP. $\alpha$ TCP is more soluble and resorbs faster than $\beta$-TCP, whereas $\mathrm{HA}$ is considered to be the most stable form of CaPs [13, 14]. $\beta$-tricalcium phosphate degrades in 6 to 12 months, while hydroxyapatite in 12 to 36 months $[15,16]$. Incorporation of various ions into the crystal lattice of the hydroxyapatite influences its physicochemical and biological properties. In the HA structure calcium ions can be substituted with $\mathrm{Mg}^{2+}$,
$\mathrm{Na}^{+}, \mathrm{K}^{+}, \mathrm{Zn}^{2+}, \mathrm{Cu}^{2+}, \mathrm{Fe}^{2+} . \mathrm{PO}_{4}^{3-}$ anions can be replaced by $\mathrm{CO}_{3}^{2-}, \mathrm{SiO}_{4}^{4-}, \mathrm{SO}_{4}^{2-}$, and $\mathrm{VO}_{4}^{3-}$, whereas $\mathrm{OH}^{-}$by $\mathrm{F}^{-}, \mathrm{Cl}^{-}$ and $\mathrm{Br}^{-}[14,17]$. Simultaneous incorporation of $\mathrm{Mg}^{2+}$ and $\mathrm{CO}_{3}^{2-}$ in the crystal lattice of HA leads to development of the biomimetic material with solubility and mechanical properties changing with respect to the undoped hydroxyapatite [18]. Ti modified hydroxyapatite has been proven to possess higher bioactivity in comparison to the non-modified HA [19].

The interesting alternative for high-temperature calcium phosphate ceramics are moldable, self-setting calcium phosphate cements (CPCs). CPCs consist of a powder and a liquid phase, which are mixed together to form a plastic paste. This paste sets and hardens in situ after implantation into the bone defects [20-22]. Calcium sulfate (CS) is well recognized not only as a biocompatible but also the osteoconductive bone graft material with a long clinical history. CS exhibits hemostatic and angiogenic properties and is easy to handle, inexpensive and readily available. Calcium sulfate can be applied to repair large bone defects even in infected areas and can be used as an efficient delivery vehicle for antibiotics, grow factors and pharmacological drugs [23-26]. This material reveals a rapid resorption by a process of dissolution and it degrades completely in 1 to 2 months $[15,16]$. Too fast resorption can be a great disadvantage. If a bone graft material resorbs faster than a new bone tissue is formed, it will not provide appropriate support in the early stages of healing.

$\mathrm{CS}$ occurs in various forms like: anhydrite $-\mathrm{CaSO}_{4}$, calcium sulfate hemihydrate $(\mathrm{CSH})-\mathrm{CaSO}_{4} \cdot 0.5 \mathrm{H}_{2} \mathrm{O}$, bassanit $\mathrm{CaSO}_{4} \cdot x \mathrm{H}_{2} \mathrm{O}(0.5 \leq x<2.0)$ and calcium sulfate dihydrate (CSD) $-\mathrm{CaSO}_{4} \cdot 2 \mathrm{H}_{2} \mathrm{O}$. CSD is obtained by the hydration of $\mathrm{CSH}$ according to the reaction (1):

$$
\begin{gathered}
2\left(\mathrm{CaSO}_{4} \cdot 0.5 \mathrm{H}_{2} \mathrm{O}\right)+3 \mathrm{H}_{2} \mathrm{O} \rightarrow 2\left(\mathrm{CaSO}_{4} \cdot 2 \mathrm{H}_{2} \mathrm{O}\right)+\mathrm{Q} \\
(\mathrm{CSH})
\end{gathered}
$$

\footnotetext{
*e-mail: aslosar@agh.edu.pl
} 
where $Q$ is the amount of heat evolved [27]. Combination of the stable hydroxyapatite phase with bioresorbable calcium sulfate can be an interesting alternative for monophasic CaPs bioceramics. These materials reveal a controlled bioresorption and good surgical handiness [28].

Scanning electron microscopy (SEM) and atomic force microscopy (AFM) are complementary methods applied in examinations of material surfaces. AFM offers numerous advantages in comparison to other microscopic techniques. It does not require a difficult sample preparation and measurements can be performed in vacuum, gaseous and liquid environments [28]. AFM proves to be an useful tool to follow changes in the surface's morphology and in the in vitro assessment behavior of biomaterials incubated in the simulated body fluid [30].

The aim of this study was to determine an influence of phase composition, surface morphology and roughness (Ra) of three cement type materials on their chemical stability and bioactive potential using an atomic force and scanning electron microscopy supported by FTIR measurements.

\section{Materials and methods of examination}

Three different calcium-phosphate powders like: magnesium doped carbonate hydroxyapatite (MgCHA), titanium doped hydroxyapatite (TiHA) and $\alpha$-tricalcium phosphate $(\alpha$-TCP) were produced by a wet chemical method. In the synthesis of magnesium doped carbonate hydroxyapatite - $\mathrm{Ca}(\mathrm{OH})_{2}$ (MERCK, Germany), $\left(\mathrm{NH}_{4}\right)_{2} \mathrm{HPO}_{4}$ (POCH, Poland), $\left(\mathrm{CH}_{3} \mathrm{COO}\right)_{2} \mathrm{Mg}$ (POCH, Poland) and $\mathrm{NH}_{4} \mathrm{HCO}_{3}(\mathrm{POCH}$, Poland) were used as starting chemical precursors for calcium, phosphorus, magnesium and carbonate ions. In order to synthesize titanium doped hydroxyapatite powder, the chemical grade reactants: $\mathrm{CaO}$ ( $\mathrm{POCH}$, Poland), 85.0 wt.\% solution of $\mathrm{H}_{3} \mathrm{PO}_{4}$ (POCH, Poland) and 15.0 wt.\% solution of $\mathrm{TiCl}_{3}$ in $10.0 \mathrm{wt} \% \mathrm{HCl}$ (MERCK, Germany) were applied. pH during the precipitation process was kept constant at 11 . Additives like: 0.3 wt. $\%$ of $\mathrm{Mg}, 12.0 \mathrm{wt} . \%$ of carbonate for $\mathrm{MgCHA}$ and $2.0 \mathrm{wt}$.\% of Ti for TiHA in proportion to HA were introduced during the syntheses. The obtained doped hydroxyapatite powders were heat treated at $400^{\circ} \mathrm{C}(\mathrm{MgCHA})$ and $1250^{\circ} \mathrm{C}$ (TiHA), ground in the ball mill to the grain size below $0.06 \mathrm{~mm}$ and sieved.

The $\alpha$-tricalcium phosphate powder was synthesized via the wet chemical method, applying the following chemical grade reagents: $\mathrm{Ca}(\mathrm{OH})_{2}(\mathrm{POCH}$, Poland) and 85 wt.\% solution of $\mathrm{H}_{3} \mathrm{PO}_{4}$ (POCH, Poland). After ageing and drying, the precipitate underwent a heating cycle at $1280^{\circ} \mathrm{C}$ for 5 hours. The obtained powder was ground in the attritor to the grain size below $0.06 \mathrm{~mm}$ and sieved. The above syntheses were described in detail in our previous papers [31, 32].

The modified hydroxyapatite powders ( $\mathrm{MgCHA}$ and $\mathrm{Ti}-$ $\mathrm{HA}$ ) were mixed with calcium sulfate hemihydrate (CSH, Acros Organics, USA) at the 2:3 weight ratio using the ball mill (MM 200 Retsch, $5 \mathrm{~Hz} / 5 \mathrm{~min}$ ). In this way, three different solid state batches, namely: MgCHA-CSH, TiHA-CSH and $\alpha$-TCP, were prepared. The 1.0 wt. $\%$ chitosan solution in 0.3 wt.\% acetic acid (Sigma-Aldrich, Germany), 1.0 wt.\% $\mathrm{Na}_{2} \mathrm{HPO}_{4}$ solution (CHEMPUR, Poland) and $1.0 \mathrm{wt} \%$ chitosan solution in 0.5 wt. \% acetic acid (Sigma-Aldrich, Germany) were applied as liquid phases to prepare three cements: A, B and C, respectively.

Crystalline phases in the initial powders (MgCHA, TiHA, $\alpha$-TCP, CSH) and cements after 14 days of hardening were determined by an X-ray diffraction analysis (XRD) using Philips X'Pert Pro diffractometer. XRD data were recorded in the $2 \theta$ range from 10 to $90^{\circ}$.

The specific surface area of the powders: MgCHA, TiHA, $\alpha$-TCP and CSH was measured by the BET method (ASAP 2010 Micromeritics). Initial and final setting times of the cement pastes were determined using a Gilmore Apparatus according to the ASTM C266-08 standard [33].

In vitro stability and bioactive potential of the obtained materials were investigated using cement samples soaked in the simulated body fluid. After 60 minutes of hardening, the cylindrical specimens (12 $\mathrm{mm}$ in diameter and $4 \mathrm{~mm}$ high) were incubated in $40 \mathrm{ml}$ of SBF and stored at $37^{\circ} \mathrm{C}$ (incubator Pol-Eko - ST1) for 7 and 28 days. SBF was prepared according to the procedure described by Kokubo [4]. pH changes during the incubation were examined in static conditions using a Hanna H198129 Combo apparatus.

Morphological changes on the surfaces of specimens were observed using a scanning electron microscopy (SEM, Nova 200 NanoSEM, FEI Company) equipped with an energy dispersive X-ray spectroscopy (EDS) and by atomic force microscopy (AFM, Multimode NanoScope IV, Veeco). The diffuse reflectance Fourier-transform infrared spectroscopy (DRIFTS, PerkinElmer, Spectrum GX) was applied to investigate changes in the phase composition of the sample's surfaces after incubation.

\section{Results and discussion}

The XRD analysis of initial MgCHA, CSH and $\alpha$-TCP powders revealed no other crystalline phases besides hydroxyapatite, calcium sulfate hemihydrate and $\alpha$-tricalcium phosphate, respectively. The heat treated TiHA consisted of four phases: hydroxyapatite (HA), $\alpha$-tricalcium phosphate ( $\alpha$-TCP), $\beta$ tricalcium phosphate $\left(\beta\right.$-TCP) and perovskite $\left(\mathrm{CaTiO}_{3}\right)(\mathrm{Ta}-$ ble 1).

Table 1

Phase composition and specific surface area of the initial powders

\begin{tabular}{ccccccc}
\hline \hline \multirow{2}{*}{$\begin{array}{c}\text { Initial } \\
\text { powder }\end{array}$} & \multicolumn{4}{c}{ Phase composition [wt.\%] } & \multirow{2}{*}{$\begin{array}{c}\text { Specific } \\
\text { surface }\end{array}$} \\
\cline { 2 - 6 } MgCHA & 100 & 0 & 0 & 0 & 0 & $74.30 \pm 0.02$ \\
\hline TiHA & 44.9 & 15.8 & 33.2 & 0 & 6.1 & $12.58 \pm 0.03$ \\
\hline$\alpha-$ TCP & 0 & 100 & 0 & 0 & 0 & $3.96 \pm 0.06$ \\
\hline CSH & 0 & 0 & 0 & 100 & 0 & $1.77 \pm 0.04$ \\
\hline
\end{tabular}


Bioactivity of cement type bone substitutes

Specific surface area of initial powders was in the range of $1.77 \mathrm{~m}^{2} / \mathrm{g}(\mathrm{CSH})$ and $74.30 \mathrm{~m}^{2} / \mathrm{g}(\mathrm{MgCHA})$. The specific surface area of starting powders decreased in the following order: MgCHA $/ 400>$ TiHA/1250 $>\alpha$-TCP $>$ CSH (Table 1).

After mixing, initial (I) and final (F) setting times of the prepared pastes depended mainly on the type of the applied powder and liquid phase. The cements set from 7 to 41 minutes. Cement $C$ showed the longest $\left(F_{C}=41 \mathrm{~min}\right)$ and cement $\mathrm{A}$ the shortest $\left(\mathrm{F}_{\mathrm{A}}=18 \mathrm{~min}\right)$ final setting time (Table 2).

Table 2

Compositions and setting times of the studied cements

\begin{tabular}{|c|c|c|c|c|c|}
\hline \multirow{2}{*}{ Cement } & \multirow{2}{*}{$\begin{array}{c}\mathrm{L} / \mathrm{P} \\
{[\mathrm{ml} / \mathrm{g}]}\end{array}$} & \multirow{2}{*}{$\begin{array}{c}\text { Powder phase } \\
\text { (P) }\end{array}$} & \multirow{2}{*}{$\begin{array}{l}\text { Liquid phase } \\
\text { (L) }\end{array}$} & \multicolumn{2}{|c|}{$\begin{array}{c}\text { Setting time } \\
\text { [min] }\end{array}$} \\
\hline & & & & $\begin{array}{l}\text { Initial } \\
\text { (I) }\end{array}$ & $\begin{array}{c}\text { Final } \\
(\mathrm{F})\end{array}$ \\
\hline A & 0.54 & $\begin{array}{c}\mathrm{MgCHA}: \mathrm{CSH} \\
-2: 3\end{array}$ & $\begin{array}{c}1 \text { wt. } \% \text { solution } \\
\text { of chitosan in } \\
0.3 \text { wt. } \% \\
\mathrm{CH}_{3} \mathrm{COOH}\end{array}$ & 9 & 18 \\
\hline B & 0.44 & $\begin{array}{c}\text { TiHA: CSH } \\
\quad-2: 3\end{array}$ & $\begin{array}{c}1 \text { wt. } \% \\
\text { solution of } \\
\mathrm{Na}_{2} \mathrm{HPO}_{4}\end{array}$ & 7 & 21 \\
\hline $\mathrm{C}$ & 0.48 & $\alpha$-ТCP & $\begin{array}{c}1 \text { wt. } \% \\
\text { solution of } \\
\text { chitosan in } \\
0.5 \text { wt. } \% \\
\mathrm{CH}_{3} \mathrm{COOH}\end{array}$ & 7 & 41 \\
\hline
\end{tabular}

XRD measurements showed differences in the phase composition of the obtained cement type materials (Table 3). 14 days after setting cement $\mathrm{A}$ composed of hydroxyapatite and CSD, while cement B contained hydroxyapatite, CSD, bassanit and perovskite. In the hardened body of cement $\mathrm{C}$ two phases like: hydroxyapatite and $\alpha$-tricalcium phosphate were found. $\mathrm{pH}$ measurements of SBF solution with soaked samples were carried out. Only small changes in $\mathrm{pH}$ were observed throughout the experiment (Fig. 1). During the whole period of incubation, i.e. 28 days, $\mathrm{pH}$ values for all examined materials maintained in the range of 7.22-7.45, which was close to the physiological level. In the case of material $\mathrm{C}$ slight decrease in $\mathrm{pH}$ occurred during the incubation and resulted in the lowest $\mathrm{pH}$ value (7.22) after 28 days.

Table 3

Phase composition of the obtained cements 14 days after setting

\begin{tabular}{ccccccc}
\hline \hline \multirow{2}{*}{ Cement } & \multicolumn{5}{c}{ Phase composition [wt.\%] } \\
\cline { 2 - 7 } & HA & $\alpha$-TCP & $\begin{array}{c}\mathrm{CSD} \\
\left(\mathrm{CaSO}_{4} \cdot 2 \mathrm{H}_{2} \mathrm{O}\right)\end{array}$ & $\begin{array}{c}\text { Bassanit } \\
\left(\mathrm{CaSO}_{4} \cdot x \mathrm{H}_{2} \mathrm{O}\right)^{a}\end{array}$ & $\begin{array}{c}\text { Perovskite } \\
\left(\mathrm{CaTiO}_{3}\right)\end{array}$ \\
\hline $\mathrm{A}$ & 34.0 & 0 & 66.0 & 0 & 0 \\
\hline B & 28.2 & 0 & 10.7 & 57.4 & 3.7 \\
\hline $\mathrm{C}$ & 9.6 & 90.4 & 0 & 0 & 0 \\
\hline
\end{tabular}

${ }^{a} 0.5 \leq x<2.0$

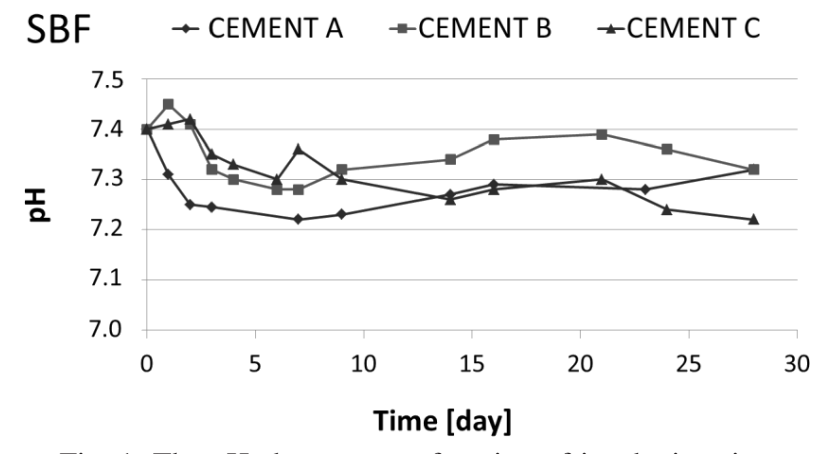

Fig. 1. The $\mathrm{pH}$ changes as a function of incubation time

SEM micrographs of the cements before and after incubation in the simulated body fluid for 7 and 28 days are presented in Fig. 2. Initial samples possessed various surface morphologies. In the case of cement $\mathrm{A}$, calcium sulfate was the only setting phase. For this material, agglomerates of $\mathrm{MgCHA}$ crystals embedded in the matrix of interconnected needlelike CSD crystals could be observed on the non-incubated surfaces. Cement B composed of two setting phases, namely tricalcium phosphate and calcium sulfate. Its initial surface differed from that of cement $\mathrm{A}$ - more calcium phosphate and less calcium sulfate crystals were visible, probably due to the presence of bassanit instead of CSD. Highly microporous surface of non-incubated cement $\mathrm{C}$ consisted of interconnected calcium phosphate crystals $(\alpha-\mathrm{TCP})$. After 7 days of incubation, the surfaces of all cements were covered with newly precipitated apatite crystals. The apatite layer formed on A and $\mathrm{B}$ materials seemed to be thinner and less uniform than for cement $\mathrm{C}$, which was coated completely with a continuous film in the short period. Morphology of apatite crystals, observed after 28 days of soaking (Fig. 3), was similar to the typical "cauliflower" morphology of bone-like apatite layer previously reported for bioactive surfaces in vitro [4, 34]. The largest agglomerates of "cauliflower-like" apatite precipitates were observed on the surface of cement C. It may be explained by the fact that materials containing resorbable calcium sulfate possessed less stable surface and could not provide firm substratum for apatite layer formation. During the process of layer-by-layer degradation, apatites precipitated on the calcium sulfate crystals were lost throughout degradation of the CSD matrix. After prolongation of incubation period to 28 days the apatite layer, for all materials, became thicker and denser. During the incubation process, a balance was reached between resorption and degradation of calcium sulfate crystals and apatite layer formation. Calcium sulfates and phosphates dissolution and precipitation processes as well as hydrolysis of $\alpha$-TCP took place. CSD phase was less stable than the HA and $\alpha$-TCP in the aqueous solution. Cements $\mathrm{A}$ and $\mathrm{B}$, due to the presence of high soluble calcium sulfates (CSD and bassanit), dissolved and degraded faster than material C. The results were confirmed by EDS analysis (Fig. 3). 
D. Siek et al.
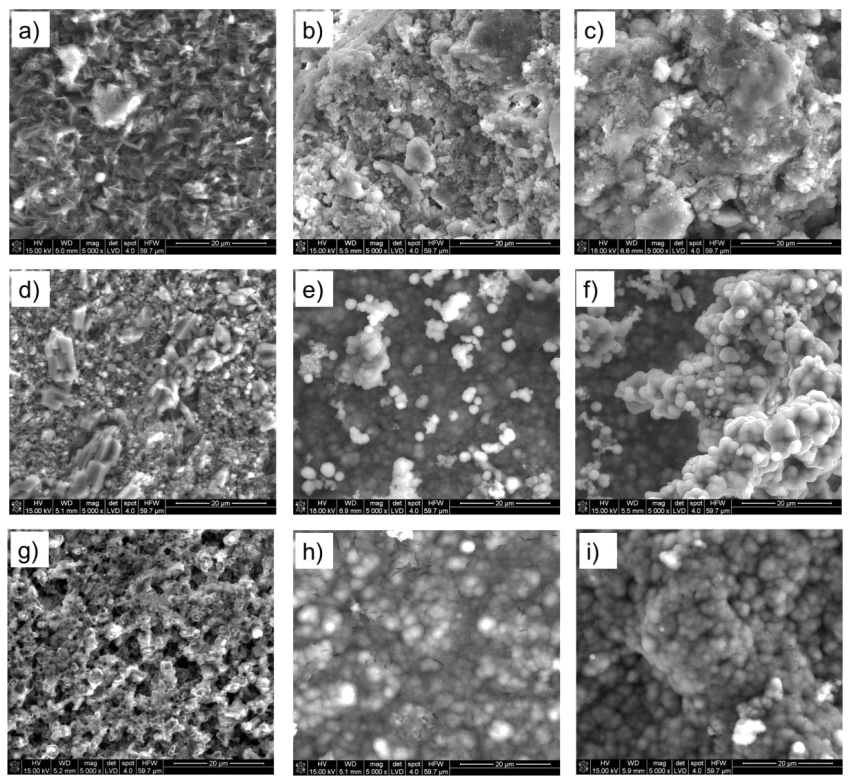

Fig. 2. SEM micrographs of cement A: non-incubated (a), after 7 days (b) and 28 days (c) of incubation in SBF, cement B: nonincubated (d), after 7 days (e) and 28 days (f) of incubation in SBF, cement C: non-incubated (g), after 7 days (h) and 28 days (i) of incubation in SBF
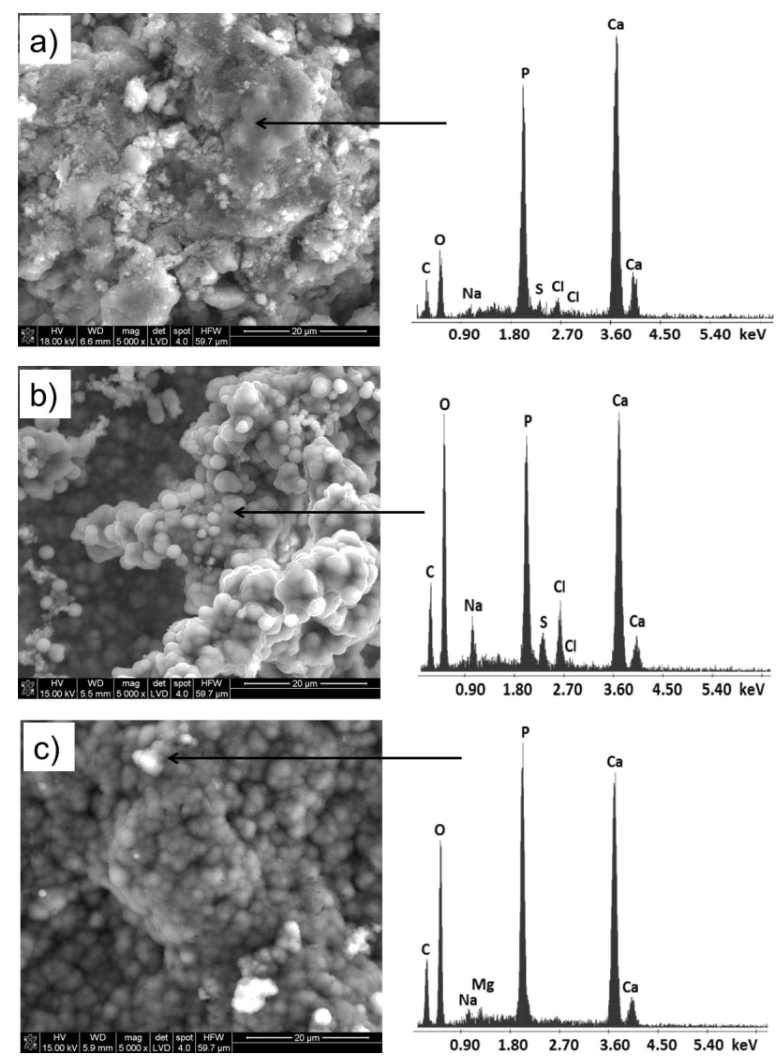

Fig. 3. EDS analysis of cement A (a), cement $\mathbf{B}$ (b) and cement $\mathbf{C}$ (c) after 28 days of incubation in SBF

AFM measurements were performed to determine changes on the surfaces of cement samples during their incubation in simulated body fluid. Measurements were performed at various places of the samples with different magnifications, starting from scan areas $100 \mu \mathrm{m} \times 100 \mu \mathrm{m}$ and ending at $1 \mu \mathrm{m}$ $\times 1 \mu \mathrm{m}$. AFM studies were repeated over the whole surface of the samples. Selected representative images were shown in the Figs. 4-6. The results clearly revealed that during soaking, surfaces of all samples were covered with evenly distributed apatite layer. These results stayed in the agreement with SEM observations. a)

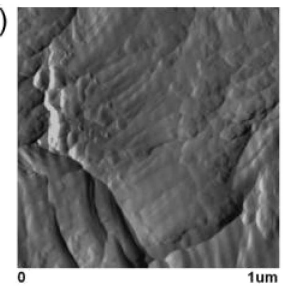

b)

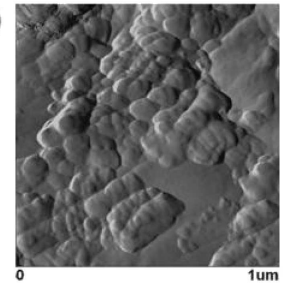

c)

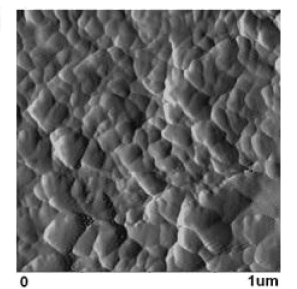

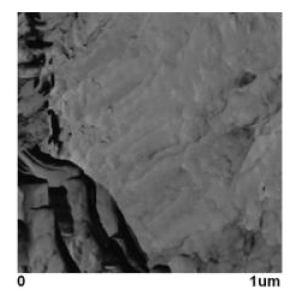
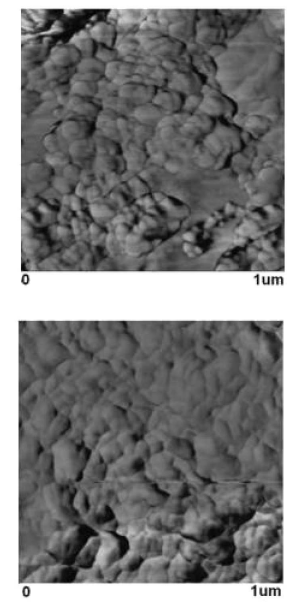

Fig. 4. 2D image (left column) and phase image (right column) of cement A: non -incubated (a), after 7 days (b), and 28 days (c) of incubation in SBF a)

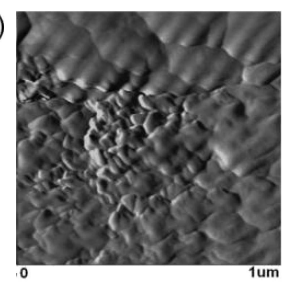

b)

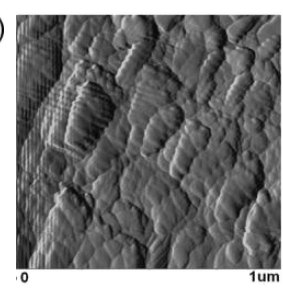

c)

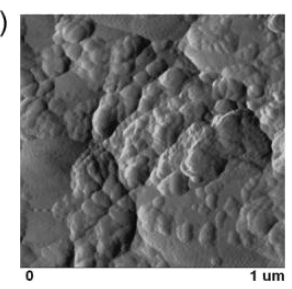

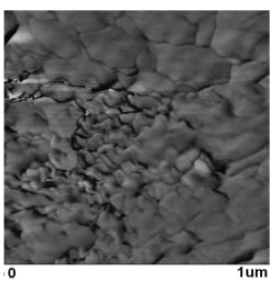
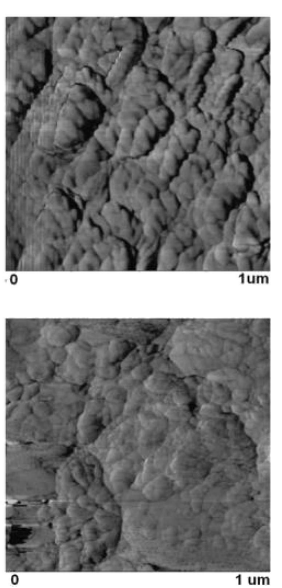

Fig. 5. 2D image (left column) and phase image (right column) of cement B: non- incubated (a), after 7 days (b), and 28 days (c) of incubation in SBF 
Bioactivity of cement type bone substitutes

a)

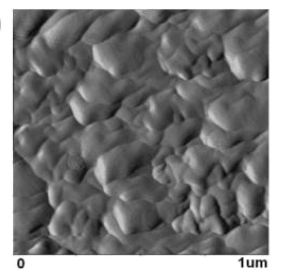

b)

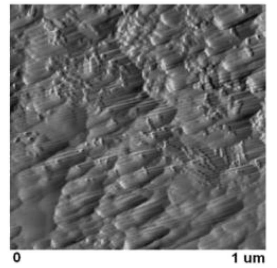

c)

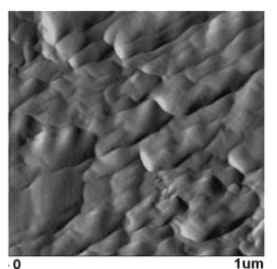

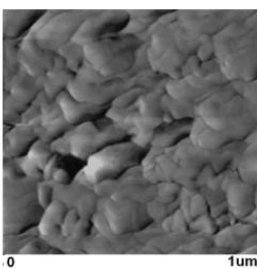
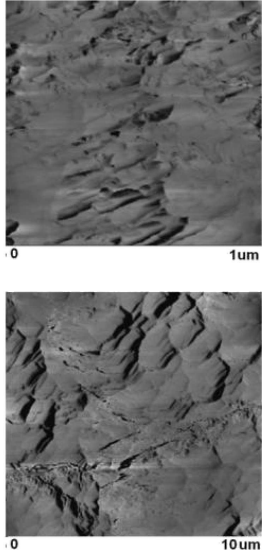

Fig. 6. 2D image (left column) and phase image (right column) of cement C: non- incubated (a), after 7 days (b), and 28 days (c) of incubation in SBF

Surface roughness is known to influence the cell behavior. Rough surfaces appeared to enhance osteoclastic attachment compared with the smooth ones [35, 36]. In the performed in vitro studies, without using cells, the roughness changes were treated as an indication of apatite layer formation (Table 4). Initial samples of the studied materials possessed various surface roughness. The non-incubated cement A revealed the lowest roughness ( $\mathrm{Ra} \sim 45 \mathrm{~nm}$ ) in comparison with two other materials. Degradation of the calcium sulfate matrix of cement $\mathrm{A}$ resulted in a significant increase in roughness after 7 days of incubation in SBF (Ra $107 \mathrm{~nm}$ ). Subsequently, the precipitation of apatite layer led to decrease of the $\mathrm{Ra}$ value to $71 \mathrm{~nm}$. Cement B revealed no significant changes in this parameter: Ra was $\sim 70 \mathrm{~nm}$ during the whole period of incubation in SBF. Cement $\mathrm{C}$ before incubation possessed the highest roughness (Ra 204 nm), which decreased drastically to $\mathrm{Ra} \sim 69 \mathrm{~nm}$ after 7 days of incubation and remained stable afterwards. It can be supposed that filling of existing pores and boundaries between grains with the newly formed apatite resulted in smoothening of the surface.

Table 4

The surface roughness $(\mathrm{Ra})$ of the cement samples after different periods of incubation in SBF

\begin{tabular}{cccc}
\hline \hline \multirow{2}{*}{ Cement } & \multicolumn{3}{c}{ Surface roughness (Ra) $[\mathrm{nm}]$} \\
\cline { 2 - 4 } & \multicolumn{2}{c}{ Time of incubation in simulated body fluid } \\
\cline { 2 - 4 } 0 days & 7 days & 28 days \\
\hline A & 45 & 107 & 71 \\
\hline B & 70 & 69 & 69 \\
\hline C & 204 & 69 & 67 \\
\hline
\end{tabular}

Infrared bands located at 510,590 and $650 \mathrm{~cm}^{-1}$, visible for the initial sample of cement $\mathrm{B}$ can be assigned to the $\mathrm{SO}_{4}$ bending vibrations (Fig. 7). Disappearance of these bands can be easily noticed as early as after 7 days of incubation in the

simulated body fluid. Furthermore, for cement A and B, decrease in the intensity of the broad band near $1100 \mathrm{~cm}^{-1}$, assigned to $\mathrm{SO}_{4}$ stretching vibration, was visible with a prolongation of the incubation time. After 28 days this band was no longer detectable. Simultaneously, an increase in the intensity of the band at $970 \mathrm{~cm}^{-1}$, corresponding to $\mathrm{PO}_{4}$ stretching vibrations, with respect to the other cement bands was observed. Changes in the DRIFT spectra indicating the formation of the apatite layer on the surface of samples incubated in the simulated body fluid, stayed in agreement with AFM and SEM observations. There was no significant difference between DRIFT spectra of the cement $\mathrm{C}$ samples in the range of $400-1800 \mathrm{~cm}^{-1}$ during the incubation. It resulted from the initial composition of the above material based only on $\alpha$-TCP which hydrolyzed to calcium-deficient hydroxyapatite (CDHA).
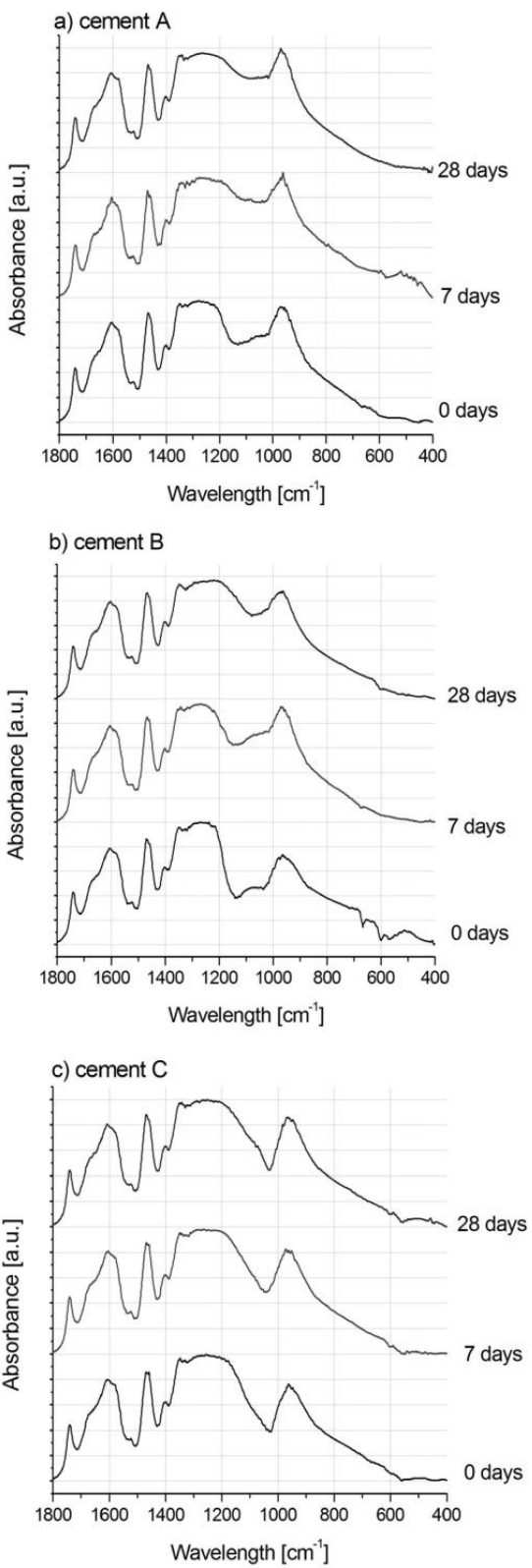

Fig. 7. DRIFTS spectra of the cement A (a), cement B (b), cement C (c): non-incubated, incubated in SBF for 7 and 28 days 
D. Siek et al

\section{Conclusions}

In our study by selecting and combining calcium sulfate hemihydrate and calcium phosphates together with different liquid phases three new cement type bone substitutes have been developed.

After setting and hardening, the obtained materials consisted of two (cements: A and C) or four crystalline phases (cement B).

The following conclusion can be drawn from the examinations:

1. All obtained materials showed a good surgical handiness and high in vitro chemical stability.

2. Developed cements set from 7 to 41 minutes. Cement $\mathrm{C}$ exhibited the longest $\left(\mathrm{F}_{\mathrm{C}}=41 \mathrm{~min}\right)$ and cement $\mathrm{A}$ the shortest $\left(\mathrm{F}_{\mathrm{A}}=18 \mathrm{~min}\right)$ final setting time.

3. Cements composed of calcium sulfate possessed less stable surface in comparison to the cement consisted of $\alpha$ tricalcium phosphate, and exhibited a higher degradation rate during incubation in SBF.

4. The highest bioactive potential showed the material which after setting consisted of hydroxyapatite $(10 \mathrm{wt} . \%)$ and $\alpha$ TCP (90 wt.\%) as it was confirmed in AFM, SEM and DRIFTS studies. Materials composed of Mg and Ti doped hydroxyapatites and calcium sulfate were also bioactive in vitro but with lower tendency to precipitation of the apatite layer when incubated in the simulated body fluid.

5. Atomic force microscopy combined with scanning electron microscopy and DRIFTS measurements have been proved to be very useful as complementary tools for assessment of in vitro material's bioactive potential.

Acknowledgements. This work has been supported by the project No UDA-POIG.01.03.01-00-005/09 co-funded by the European Union and the Polish Ministry of Science and Higher Education.

\section{REFERENCES}

[1] P. Janicki and G. Schmidmaier, "What should be the characteristics of the ideal bone graft substitute? Combining scaffolds with growth factors and/or stem cells", Injury 42, 77-81 (2011).

[2] T. Kokubo, "Design of bioactive bone substitutes based on biomineralization process", Mater Sci. Eng. C 25 (2), 97-104 (2005).

[3] M. Nowak, I. Firkowska, and M. Giersig, "Nanostructured bone-like scaffolds for restoration of trabecular bone remodeling capability", Bull. Pol. Ac.: Tech. 59 (1), 57-61 (2011).

[4] T. Kokubo and H. Takadama, "How useful is SBF in predicting in vivo bone bioactivity?", Biomaterials 27 (15), 2907-2915 (2006).

[5] T. Kokubo, S. Ito, M. Shigematsu, S. Sakka, and T. Yamamuro, "Fatigue and life-time of bioactive glass-ceramic A-W containing apatite and wollastonite", J. Mater. Sci. 22 (11), 4067-4070 (1987).
[6] L.L. Hench and E.C. Ethridge, Biomaterials: An Interfacial Approach, Academic Press, New York, 1982.

[7] N.A.F. Almeida and M.H.V. Fernandes, "Effect of glass ceramic crystallinity on the formation of simulated apatite layers", Mater. Sci. Forum 514-516, 1039-1043 (2006).

[8] M. Kamitakahara, "Novel Bone-Repairing Materials: Bioactive Organic-Inorganic Hybrids", in: Ceramics and Composite Materials: New Research, ed. B.M. Caruta, Nova Science, New York, 2006.

[9] T. Kokubo, S. Ito, Z. Huang, T. Hayashi, S. Sakka, T. Kitsugi, and T. Yamamuro, "Ca,P-rich layer formed on high-strength bioactive glass-ceramic A-W”, J. Biomed. Mater. Res. 24, 331343 (1987).

[10] T. Kokubo, T. Hayashi, S. Sakka, T. Kitsugi, and T. Yamamuro, "Bonding between bioactive glasses, glass-ceramics or ceramics in a simulated body fluid", Yogyo-Kyokai-Shi 95, 785-791 (1987).

[11] S.V. Dorozhkin, "Calcium orthophosphate", J. Mater. Sci. 42 (4), 1061-1095 (2007).

[12] H. Liu and T.J. Webster, "Bioinspired Nanocomposites for Orthopedic Applications", in: Nanotechnology for the Regeneration of Hard and Soft Tissues, ed. T.J. Webster, World Scientific Publishing Co., Singapore, 2007.

[13] B. McKay, S. Peckham, and J. Scifert, "Biologics to promote spinal fusion", in: Spine Technology Handbook, eds. S.M. Kurtz, A.A. Edidin, Elsevier Academic Press, Boston, 2006.

[14] E. Boanini, M. Gazzano, and A. Bigi, "Ionic substitutions in calcium phosphates synthesized at low temperature", Acta Biomater. 6 (6), 1882-1894 (2010).

[15] C. Knabe, A. Houshmand, G. Berger, P. Ducheyne, R. Gildenhaar, I. Kranz, and M. Stiller, "Effect of rapidly resorbable bone substitute materials on the temporal expression of the osteoblastic phenotype in vitro", J. Biomed. Mater. Res. A 84 (4), 856-868 (2008).

[16] A.K. Garg, "Review of bone-grafting materials", in: Bone Biology, Harvesting, and Grafting for Dental Implants: Rationale and Clinical Applications, ed. A.K. Garg, Quintessence Publishing Co., Chicago, 2004.

[17] W. Mróz, A. Bombalska, S. Burdyńska, M. Jedyński, A. Prokopiuk, B. Budner, A. Ślosarczyk, A. Zima, E. Menaszek, A. Ścisłowska-Czarnecka, and K. Niedzielski, "Structural studies of magnesium doped hydroxyapatite coatings after osteoblast culture", J. Mol. Struct. 977 (1-3), 145-152 (2010).

[18] R.Z. LeGeros, R. Kijkowska, C. Bautista, and J.P. LeGeros, "Synergistic effects of magnesium and carbonate on properties of biological and synthetic apatites", Connect Tissue Res. 33 (1-3), 203-209 (1955).

[19] A. Ślósarczyk, A. Zima, Z. Paszkiewicz, J. Szczepaniak, A.H. De Aza, and A. Chróścicka, "The influence of titanium on physicochemical properties of Ti-modified hydroxyapatite materials", Ceramic Materials 62 (3), 369-375 (2010).

[20] M.P. Ginebra, T. Traykova, and J.A. Planell, "Calcium phosphate cements as bone drug delivery systems: a review", J. Control Release 113 (2), 102-110 (2006).

[21] M. Bohner, "Physical and chemical aspects of calcium phosphates used in spinal surgery", Eur. Spine J. 10, 114-121 (2001).

[22] E. Fernandez, F.J. Gil, M.P. Ginebra, F.C.M Driessens, and J.A. Planell, "Production and characterization of new calcium phosphate bone cements in the $\mathrm{CaHPO}_{4}-\alpha \mathrm{Ca}_{3}\left(\mathrm{PO}_{4}\right)_{2}$ system: $\mathrm{pH}$, workability and setting times", J. Mater. Sci. Mater. Med. 10, 223-230 (1999). 


\section{Bioactivity of cement type bone substitutes}

[23] S. Mamidwar, M. Weiner, H. Alexander, and J. Ricci, "In vivo bone response to calcium sulfate/poly L-lactic acid composite", Implant Dent 17 (2), 208-216 (2008).

[24] H.M. Jung, G.A. Song, Y.K. Lee, J.H. Baek, H.M. Ryoo, G.S. Kim, P.H. Choung, and K.M. Woo, "Modulation of the resorption and osteoconductivity of alpha-calcium sulfate by histone deacetylase inhibitors", Biomaterials 31 (1), 29-37 (2010).

[25] S.L. Bahn, "Plaster: a bone substitute", Oral Surg. Oral Med. Oral Pathol. 21 (5), 672-681 (1966).

[26] M.V. Thomas and D.A. Puleo, "Calcium sulfate: Properties and clinical applications", J. Biomed. Mater. Res. B Appl. Biomater. 88 (2), 597-610 (2009).

[27] N.B. Singh and B. Middendorf, "Calcium sulphate hemihydrate hydration leading to gypsum crystallization", Prog. Cryst. Growth Charact. Mater. 53 (1), 57-77 (2007).

[28] M. Nilsson, J.S. Wang, L. Wielanek, K.E. Tanner, and L. Lidgren, "Biodegradation and biocompatability of a calcium sulphate-hydroxyapatite bone substitute", J. Bone Joint Surg. Br. 86 (1), 120-125 (2004).

[29] D.C. Martin, J.R. Ojeda, J.P. Anderson, and P. Pingali, "Atomic force microscopy of polymer droplets", in: Atomic Force Microscopy/Scanning Tunneling Microscopy, eds. S.H. Cohen, M.T. Bray, M.L. Lightbody, Plenum Press, New York, 1994.

[30] I.B. Leonor, A. Ito, K. Onuma, N. Kanzaki, and R.L. Reis, "In vitro bioactivity of starch thermoplastic/hydroxyapatite com- posite biomaterials: an in situ study using atomic force microscopy", Biomaterials 24 (4), 579-585 (2003).

[31] A. Zima, Z. Paszkiewicz, D. Siek, J. Czechowska, and A. Ślósarczyk, "Study on the new bone cement based on calcium sulfate and $\mathrm{Mg}, \mathrm{CO}_{3}$ doped hydroxyapatite", Ceram Int 38 (6), 4935-4942 (2012).

[32] J. Czechowska, Z. Paszkiewicz, A. Zima, D. Pijocha, and A. Ślósarczyk, "Influence of heat treatment of titanium-doped hydroxyapatite (TiHA) on properties and in vitro behaviour of calcium sulfate-TiHA composites", Ceramic Materials 63 (4), 758-764 (2011).

[33] ASTM C266-04, ASTM Annual Book of standards, "Standard test method for time setting of hydraulic-cement paste by gillmore needles", PA 19428-2959, USA.

[34] M. Topic, T. Ntsoane, and R.B. Heimann, "Microstructural characterisation and stress determination in as-plasma sprayed and incubated bioconductive hydroxyapatite coatings", Surf. Coat Technol. 201 (6), 3633-3641 (2006).

[35] K. Gomi and J.E. Davies, "Guided bone tissue elaboration by osteogenic cells in vitro", J. Biomed. Mater. Res. 27 (4), 429 431 (1993).

[36] T. Ballet, L. Boulange, Y. Brechet, F. Bruckert, and M. Weidenhaupt, "Protein conformational changes induced by adsorption onto material surfaces: an important issue for biomedical applications of materials science", Bull. Pol. Ac.: Tech. 58 (2), 303-315 (2010). 